\title{
THE EFFECTS OF VITAMIN B12, VITAMIN D, FERRITIN LEVEL, NEUTROPHIL/MONOCYTE RATIO AND SOME BLOOD PARAMETERS ON GENITAL WARTS PRESENCE, THE NUMBER OF LESIONS, AND RECURRENCE
}

\author{
Aslan Demir ${ }^{1}$ and Semih Guder ${ }^{1}$ \\ ${ }^{1}$ Bezmialem Foundation University Medical Faculty Hospital
}

November 3, 2020

\begin{abstract}
Objective Human Papillomavirus (HPV) that is an epitheliotropic virus that infects basal keratinocytes on epithelia of skin and mucosal membranes has been isolated in genital warts (GWs). The relationships between cancer caused by HPV and some vitamins such as B12 and vitamin D and iron metabolism, as well as leukocytes and their ratios have been investigated in the literature. Our aim is to evaluate these relatioships at the level of GW as well as to analyse if there is a relationship between the investigated parameters and lesion numbers. Materials and Methods Data were obtained from 98 and 94 patients for group 1 and 2, including GW patients and healthy people, respectively. The blood parameters and lesion numbers in the GW patients were reported and analysed in terms of vitamin B12 and D, ferritin and leucocytes. Results A correlation was established between lesion numbers, age and midcorpusculer volume (MCV) $(\mathrm{p}<0.05)$. There was no any correlation between lesion numbers and recurrent cases. According to the comparative analysis, there were a difference in terms of ferritin, neutrophil, monocyte, hemoglobine, MCV and neutrophil/monocyte ratio between groups. The cutoff values for neutrophil, monocyte and N/M ratios were 56.45, 4.91, and 7.825, respectively Conclusion While our study showed that GW development may be affected by blood ferritin levels and in this situation, MCV, neutrophil, monocyte and N / M ratios may change, a relation was found between lesion numbers and age and mean MCV values only. However, further studies are needed to clarify this issue.
\end{abstract}

ORIGINAL ARTICLE

THE EFFECTS OF VITAMIN B12, VITAMIN D, FERRITIN LEVEL, NEUTROPHIL/MONOCYTE RATIO AND SOME BLOOD PARAMETERS ON GENITAL WARTS PRESENCE, THE NUMBER OF LESIONS, AND RECURRENCE

Running Title: Vitamin B12/D, neutrophil/monocyte and genital warts

Acknowledgements: None

Sources of funding: None

Conflict of interests: None

\section{ABSTRACT}

Objectives

Human Papillomavirus (HPV) that is an epitheliotropic virus that infects basal keratinocytes on epithelia of skin and mucosal membranes has been isolated in genital warts (GWs). The relationships between cancer 
caused by HPV and some vitamins such as B12 and vitamin D and iron metabolism, as well as leukocytes and their ratios have been investigated in the literature. Our aim is to evaluate these relatioships at the level of GW as well as to analyse if there is a relationship between the investigated parameters and lesion numbers.

\section{Methods}

Data were obtained from 98 and 94 patients for group 1 and 2, including GW patients and healthy people, respectively. The Neutrophil / Monoctye ratio, and lesion numbers in the GW patients were reported and analysed in terms of vitamin B12 and D, ferritin and leucocytes.

\section{Results}

A correlation was established between lesion numbers, age and midcorpusculer volume (MCV) $(\mathrm{p}<0.05)$. There was no any correlation between lesion numbers and recurrent cases. According to the comparative analysis, there were a difference in terms of ferritin, neutrophil, monocyte, hemoglobine, MCV and neutrophil/monocyte ratio between groups. The cutoff values for neutrophil, monocyte and N/M ratios were $56.45,4.91$, and 7.825 , respectively

\section{Conclusion}

While our study showed that GW development may be affected by blood ferritin levels and in this situation, MCV, neutrophil, monocyte and N / M ratios may change, a relation was found between lesion numbers and age and mean MCV values only. However, further studies are needed to clarify this issue.

Keywords: Genital wart, Neutrophil/Monocyte ratio, Vitamine B12, Vitamine D, ferritin

\section{What is already known about this topic?}

In the literature, the relationship between HPV and nutrition has been investigated in terms of some vitamins such as vitamin B12, and D, and iron metabolism. Although the effects of these vitamins have been reported over the immune system in general, they have been published in contrary studies ${ }^{7-9}$. In addition, some leukocytes and some ratios relationships between each other have been investigated in some cancers due to HPV. The reason for such studies depends on the results of some laboratory studies in which cytokines that stimulate the secretion of neutrophils from the bone marrow are secreted from tumor cells. Therefore, the number and ratios of leukocytes (neutrophils, monocytes, and lymphocytes), which play an important role in the host's immune response against infections and tissue damage, have attracted attention in some studies $^{1,5,11-13}$

\section{What does this article add?}

Some labratory studies have demonstrated that tumor cells may release cytokines that stimulate the release of neutrophils from the bone marrow, which results in an elevation of the leucocytes ${ }^{5,19}$. We can interpret this information so that the larger tumor or metastasis, the more leukocytes. This interpretation may also explain the difference between studies. Because in each study, different leukocytes and rates to each-other, and cancers of different stages and sizes were studied. Our difference in this study is to investigate whether these parameters and their ratios with each-other have a relationship between the disease and the diagnostic value of the disease, only at the level of genital warts formation, where cancer has not yet developed. The most important difference of our study from the ones in the literature is that patients who have just been met to the virus and have not yet developed malignancy were included in our study, while the patients who have already developed malignancy had been analyzed in other studies in the literature.

\section{INTRODUCTION}

Genital Human Papillomavirus (HPV) that is an epitheliotropic DNA virus that infects basal keratinocytes on surface epithelia of skin and mucosal membranes has been isolated in genital warts $(\mathrm{GWs})^{1-3}$. The most common types among about 200 types of HPV are type $6,11,2,40,42,43$ and $54^{2,4}$. HPV infections are one of the most common sexually transmitted infections worldwide. It is an important public health problem 
not only because of its high prevalence and transmittance, but also because its some types play a precursor in some cancers such as cervical, oropharingeal and other anogenital cancers ${ }^{1,4-6}$. HPV 6 and 11 types are low-risk types in terms of malignancy and are responsible for about $90 \%$ of GWs. Approximately $15 \mathrm{HPV}$ types, with the most important types 16 and 18, pose a high-risk for malignancy and account for $70 \%$ of cervical cancers in women ${ }^{4}$.

In the literature, the relationship between HPV and nutrition has been investigated in terms of some vitamins such as vitamin B12, and D, and iron metabolism. Although the effects of these vitamins have been reported over the immune system in general, they have been published in contrary studies ${ }^{7-9}$. In addition, some leukocytes and some ratios relationships between each other have been investigated in some cancers due to HPV. The reason for such studies depends on the results of some laboratory studies in which cytokines that stimulate the secretion of neutrophils from the bone marrow are secreted from tumor cells. Therefore, the number and ratios of leukocytes (neutrophils, monocytes, and lymphocytes), which play an important role in the host's immune response against infections and tissue damage, have attracted attention in some studies $^{1,5,11-13}$.

While these blood parameters and their ratios are studied in cancers caused by HPV, according to our research in the literature, since the correlation between GW itself and blood parameters have not been investigated, our study will be the first study. Based on our clinical observation, the number of GWs can change in each patient. We aimed to analyze whether there is a correlation between blood parameters (Neutrophil / Monocyte ratios, ferritin, Vitamin B12 and D) and GWs and its lesion numbers as well as the difference between groups in terms of these parameters.

\section{MATERIALS AND METHODS}

The study was designed as an observational and prospective study. Permission was obtained from the Regional Ethics. In our study includes group 1 which consists of men older than 20 years old who had applied to the urology or dermatology clinic of our institute with the complaint of warts in their genital areas, and who did not have any other hematological and gastrointestinal problems, and group 2 which consists of the participants who have not GW in their genital area in the control group enrolled from the check-up unit between 06.2019 and 06.2020. Informed consent was obtained from all patients.

GW and its numbers were determined by physical examination and reported. Also, recurrent cases were reported, as well. Venous blood samples were taken from these patients for complete blood count (lymphocyte, neutrophil, monocyte, hemoglobin, red blood cell, midcorpuscular volume, platelet and platelet volume), vitamin D, B12, and ferritin levels analysis. These blood parameters were measured by using CellDyne 4000 for complete blood count and ArchitectPlus, ci4100 for the other parameters (Abbot laboratories, North Chicago, IL, USA). Patients with hematological, gastrointestinal or systemic diseases, in case study parameters may be affected, were excluded from the study. Groups 1 and 2 were formed for wart and control group, respectively. The blood parameters and their ratios with each-other were compared between groups and the correlation between complete blood count and ratios and the lesion numbers were analyzed. In addition to these, it was analyzed whether there is a correlation between lesion numbers and recurrence.

\section{Statistical Analysis}

Data were analyzed using SPSS-22 for Windows (SPSS, Inc., Chicago, IL) software. Statistical analyses of the means of continuous variables were performed with Student's $t$-test and a Mann-Whitney U test for non-homogenic distribution. The correlation between complete blood count and their ratios with each-other and the lesion numbers was analyzed with the Pearson's correlation and lineer regression was done when established a correlation between blood parameters. Receiver operating characteristics (ROC)- derived area under curve (AUC) were estimated to evaluate the diagnostic accuracy of blood parameters and their ratios with eache-other. The AUC, sensitivity, and specificity were compared using their $95 \%$ confidence intervals. Results were considered significant at $\mathrm{p}<0.05$.

\section{RESULTS}


A total of 98 and 94 patients were included in the study for group 1 which consists of the patients with GWs and group 2 which consists of healthy participants, respectively.

Twenty-nine patients in the first group $(29.9 \%)$ were patients who had warts before and treated and repeated their disease.

A positive correlation was established between age and GWs presence $(\mathrm{p}<0.05$, Pearson correlation coefficient; 0.15). Depending on this result, we applied a lineer regression analysis between age and GWs presence, and $\mathrm{R}$ square was found to be 0.23 with a coefficient of 0.15 , $(\mathrm{p}<0.03)$.

According to the correlation analysis between lesion numbers and blood parameters and with their ratios with each-other, we only found a positive correlation of lesion numbers with the age and midcorpuscular volume (MCV) of the red blood cell (RBC), which had Pearson's correlation coeffficients of 0.25 and 0.20 , respectively $(\mathrm{p}<0.05$, Table 1$)$. Also, we found a positive correlation between age and MCV of the RBC $(\mathrm{p}=0.009)$, which had Pearson's correlation coefficient of 0.18. Depends on these results, we applied a lineer regression for age and MCV of the RBC. The R squares were found as 0.06 and $0.04(\mathrm{p}<0.05)$, which had coefficients of 0.25 and 0.20 respectively, (Table 1 ). In addition to these, we applied the correlation analysis between lesion numbers and the presence of the recurrent cases in the subgroup analysis. There was no correlation between lesion numbers and the presence of recurrent cases $(\mathrm{p}>0.05)$ (Table 2).

According to the comparative analysis of the groups, there were no differences between the two groups in terms of the mean age, Vit B12 and D levels, leucocytes, lymphocytes, hemoglobine (Hb), RBC, platelets, plateletes volume, lymphocytes/monocytes and neutrophyl/lymphocytes ratios ( $p>0.05$, Table 3 ). We found differences in terms of ferritine levels, the percent of neutrophyl and monoctyte counts, MCV of the RBC, and neutrophil/monocyte ratios between groups 1 and $2(\mathrm{p}<0.05$, Table 3$)$.

According to the comparative analysis of the subgroups which consists of recurrent cases, the mean hemoglobine level in the recurrent positive and negative subgroups was $15.53 \pm 1.13$ and $14.93 \pm 1.23$, respectively, $\mathrm{p}<0.05$, Table 3$)$. There was no difference in terms of the other blood parameters in the subgroup analysis (Table 3 ).

The AUCs of the ROC curve for the ferritin, neutrophil, monocytes, MCV of the RBC, and neutrophil/monocyte ratios were $0.57 \pm 0.04,0.59 \pm 0.04,0.39 \pm 0.04,0.55 \pm 0.04$, and $0.61 \pm 0.04$. (Figure 1-2). The best cut-off values for the same parameters were defined as $139.74,56.45,4.91,91.15$, and 7.825 , respectively

\section{DISCUSSION}

HPV invades cells of the basal layer of the epidermis, penetrating skin and mucosal microabrasions in genital area. A latency period of months to years may ensue ${ }^{12}$. The main risk factor for HPV transmission is the number of sex partners as well as age at first intercourse, barrier contraceptive use, co-infections, male sexual behavior, and male circumcision ${ }^{12}$. In our study, a positive correlation was established between age and GWs presence $(\mathrm{p}<0.05$, Pearson correlation coefficient; 0.15). We have associated this result with the increasing number of sex partners and sexual intercourse cumulatively as age increases. For that reason we applied a lineer regression analysis between age and GWs status, and R square was found to be 0.23 with a coefficient of $0.15(\mathrm{p}<0.03)$.

Direct visual inspection with bright light and magnification is used at the diagnosis of GWs. Biopsy is not reccomended routinely, but may be of interest in case of refractory treatments or when neoplasia is suspected $^{3,12}$. It can be said on the basis of the physical examination that the lesion numbers of patients with GWs differ from patient to patient. Depending on this clinical observation, we aimed to analyze the relationship between the lesion numbers and age and some blood parameters and their ratios with each-other . To the best of our knowledge, our study is the first on this subject. According to our results, it could not be found a correlation between lesion numbers and some blood parameters except age and MCV of the RBC (Table 1). Also, we found a positive correlation between age and MCV ( $\mathrm{p}=0.009)$, which had Pearson's correlation coefficient of 0.18 . Depends on these results, we applied a lineer regression for age and MCV. The $\mathrm{R}$ squares were found as 0.06 and $0.04(\mathrm{p}<0.05)$, which had coefficients of 0.25 and 0.20 respectively, (Table 
1). The relationship between lesion numbers and age may be associated with the cumulative effect of the intercourse and sexual partners and its varieties, but the pathway the relationship between lesion numbers and MCV needs further studies. Consistent with our finding, there are studies in the literature reporting that the most important risk factor for GW is the lifetime number of sexual partners ${ }^{12}$. It may be said that the more partners, the more wart risk.

The treatment of GWs is not easy all the time because the virus produces small amounts of HPV antigen, which eludes the immune system, and HPV DNA may still reside in the margins outside of the treated area. The ratio of the recurrence was $29.9 \%$ in our study population. (Table 2). According to this understanding, a relationship could be expected between recurrent cases and the lesion numbers. However, in our analysis, no correlation was found between the lesion numbers and recurrent cases ( $>00.05$, Table 2). This can be explained by the fact that HPV DNA remains within the boundaries of the treated area despite treatment ${ }^{12,13}$. Another comment that can be made on this issue is that the virus's own contagiousness may continue due to the late application of the patient for treatment.

Most HPV infections are temporary and may become undetectable in about 2 years. Unfortunately, HPV's inability to eradicate, creating a permanent condition for HPV is thought to play a role in the development of anogenital cancer or another one ${ }^{14}$. The reason for the inability of HPV eradication is because we know little about viral clearance and latency ${ }^{12}$. The immun system plays a key role during HPV-associated carcinogenesis. For instance, about $90 \%$ of immunocompetent HPV-infected patients resolve spontaneously within three years and less than $1 \%$ progress invasive cancer ${ }^{1}$. Cell-mediated immunity is considered to be crucial for clearance of HPV infections and HPV-related malignancy is more prevalent in immunocompromised individuals ${ }^{15}$. The HPV infection and life cycle of the virus is exclusively within epidermal keratinocytes. Keratinocytes themselves are considered as a component of the innate immun system ${ }^{1}$. In the formation mechanism of HPV-related precancerous lesions and / or cancers, cell transformation should be triggered in keratinocytes. This cell transformation begins to disrupt the function of host cell cycle regulatory proteins in infected keratinocytes, where high risk-HPV E6 and E7 oncoproteins are effective ${ }^{1,16}$. To induce a cytotoxic $\mathrm{T}$ cell response against infected keratinocytes, skin resident antigen presenting cells must initiate and coordinate innate and adaptive immun responses ${ }^{1}$. In addition to these knowledge, leucocytes, mainly including neutrophils, monocytes, and lymphocytes, have an importance in the host innate immune response to infection and damaged tissue ${ }^{1}$.

The role of inflammation has been well investigated in cancer biology ${ }^{10}$ and the circulating leukocyte count appears to be elevated as well as functionally different in cancer patients versus healthy population ${ }^{17,18}$. The ratios between neutrophil and other leukocytes can reflect the status of systematic inflammation and these ratios have been demonstrated as a prognostic and predictive factor of disease activity in various cancers and accumalating evidences have suggested that pretreatment the ratios between neutrophil and the other leucocytes such as monocytes and lymphocytes are related to the prognosis of a variety of some cancers $5,6,10,11,17,18$. Tumor-infiltrating neutrophils can release cytokines to promote angiogenesis, which leads to tumor growth and metastasis ${ }^{5}$. Some labratory studies have demonstrated that tumor cells may release cytokines that stimulate the release of neutrophils from the bone marrow, which results in an elevation of the leucocytes ${ }^{5,19}$. We can interpret this information so that the larger tumor or metastasis, the more leukocytes. This interpretation may also explain the difference between studies. Because in each study, different leukocytes and rates to each-other, and cancers of different stages and sizes were studied. Our difference in this study is to investigate whether these parameters and their ratios with each-other have a relationship between the disease and the diagnostic value of the disease, only at the level of genital warts formation, where cancer has not yet developed.

There was no statistical difference between the group with GW and the control group in terms of B12, vitamin $\mathrm{D}$, leukocyte count, lymphocyte percentage, RBC count, platelet count and volume, and neutrophil/lymphocyte parameters. Our findings show that GW formation is not affected by B12 and vitamin D levels (Table 3). Interestingly, however, ferritin levels were found to be significantly higher in the GW group than in the control group ( $132.59 \pm 86.49$ and $106.81 \pm 64.5$ for group 1 and 2 , respectively, $\mathrm{p}<0.05$, Table 3 ). 
In our results, it is compatible with the results of the work done by Siegel et $\mathrm{al}^{20}$. Iron can exist in several oxidation states, a property that supports electron transfer for ATP generation as well as promotion of reactive oxygen species (ROS). ROS produced by elevated iron has been shown to directly alter the viral activity of several cancer-causing viruses, including HPV. Rising iron stores may decrease probability of clearing new HPV infection, possibly by promoting viral activity and contributing to oxidative DNA damage ${ }^{20}$. According to our results, high ferritin levels may put the patients at risk for new or persistent GW infection. However, further studies are needed to examine the relationship between iron status and GW formation. The AUC of the ROC curve for the ferritin level was 57.9\% (95\% CI: 49.3-66.5) (Figure 1). The best cut-off value for ferritin level was defined as 139.74, which had a sensitivity of $49 \%$ and spesificity of $66 \%$ (Table 4 ). The risk may be more important in terms of percancerous lesions at the point of the cut-off value.

Mean MCV values were also statistically higher in group 1 than in group 2 ( $87.5+-4.16$ and 86.75+-4.18, for groups 1 and 2, respectively, p <0.05, Table 3). The AUC of the ROC curve for the MCV was $55.8 \%$ (95\% CI: 47.7-63.9) (Figure 2). The best cut-off value for MCV was defined as 91.15 which had a sensitivity of $19 \%$ and spesificity of $6 \%$ (Table 4). This data indicate that elevated MCV was connected with GW presence. The iron metabolism pathway may be one of the pathways that explains this situation. However, further studies are needed to examine on this pathway. Our results show that the percentage of neutrophil is significantly higher than the control group, while the percentage of monocyte is significantly lower than that of the control group (for neutrophyl $(\mathrm{N})$ percentage: $56.06+-7.93$ and $53.33+-8.00$, for groups 1 and 2 , respectively, $\mathrm{p}=0.01$, Table 3 ; for monocyte $(\mathrm{M})$ percentage: $7.51+-1.66$ and $8.16+-1.84$ for groups 1 and 2, respectively, $\mathrm{p}=0.01$, Table 3 ). As a result of this situation, $\mathrm{N} / \mathrm{M}$ ratio was found to be significantly higher than the control group ( $7.73+-2.14$ and $6.96+-2.12$ for groups 1 and 2 , respectively, $\mathrm{p}=0.01$, Table 3 ). The patients who have these values and their female partners may be followed more cautiously with regard to development precancerous lesions or the development of malignancy. For instance the determining of the HPV type can be realised for such patients in order to understand whether the type in the patient is related with cancer formation or not.

When compared our results with the literature, statistically significant differences were found between leukocyte and their ratios between groups, as expected except lymphocyte, N/L, platelet count and its volume ( $>0.05$, Table 3). The most important difference of our study from the ones in the literature is that patients who have just been met to the virus and have not yet developed malignancy were included in our study, while the patients who have already developed malignancy had been analyzed in other studies in the literature. The reason for the difference in the results of some studies in the literature may be that patients with malignancies of different stages and sizes were included in those studies ${ }^{5,6,10,11,21-24}$.

The AUC of the ROC curve for the neutrophil and monocyte percentage was 59.8\% (95\% CI: 51.8-67.8) and 39.7\% (95\% CI:31.8-47.7), respectively (Figure 2). The best cut-off value for neutrophil and monocyte percentage was defined as 56.45 , which had a sensitivity of $49 \%$ and spesificity of $29 \%$ and as 4.91 , which had a sensitivity of $98 \%$ and spesificity of $97 \%$, respectively (Table 4). Also, The AUC of the ROC curve for $\mathrm{N} / \mathrm{M}$ was $61.6 \%$ (95\% CI: 53.7-69.5) (Figure 2). The best cut-off value for N/M was defined as 7.825, which had a sensitivity of $48 \%$ and spesificity of $28.7 \%$ (Table 4 ). The pooled data indicated that elevated neutrophil and N/M ratios were connected with GWs.

In the subgroup analysis in which recurrent cases were examined, no statistical difference was found between recurrent and new infected cases except Hb levels (Table 3).

Our results and the published ones in the literature suggest that these investigated parameters may have different biological effects on tumor progression, the development of metastases and response to the applied treatment. Also, these results suggest that there may be an interaction between these blood parameters in regulating protumor activity versus antitumor activity ${ }^{5}$.

The studies examining the relationship between the blood parameters and the development of malignancy are cheap studies that can shed light on the diagnosis, treatment and follow-up of these diseases. In this period where the awareness of the fact that the resources in the world should be used more cautiously, further 
studies are needed to evaluate the secrets of those such cheap examinations in order to use them correctly.

Lacks of study

The lack of HPV typing is our limitation of work.

\section{CONCLUSION}

While our study showed that genital wart development may be affected by blood ferritin levels and in this situation, MCV, neutrophil, monocyte and $\mathrm{N} / \mathrm{M}$ ratios may change, a relation was found between lesion numbers and age and mean MCV values only. However, further studies are needed to clarify this issue.

\section{Funding: Not applicable}

\section{Conflicts of interest / Competing interests: Not applicable}

\section{Acknowledgements : None \\ REFERENCES}

1. Bashaw AA, Leggat GR, Chandra J, et al. Modulation of antigen presenting cell functions during chronic HPV infection. Papillomavirus Research 2017;4:58-65

2. Dareng EO, Adebamowo SN, Famooto A, et al. Prevalence and incidence of genital warts and cervical Human papillomavirus infections in Nigerian women. BMC Infectious Diseases, 2019;19:27

3. Kilciler M, Bedir S, Erdemir F, et al. Condylomata acuminata of external urethral meatus causing infravesical obstruction. Int Urol and Nephrol 2007;39:107-109

4. Heidegger I, Pichler R, Muller B, et al. Is real-time PCR the correct method to evaluate the incidence of human papillomavirus in prepuces of asymptomatic boys and men? World J Urol 2014;32:1199-1204

5. Huang SH, Waldron JN, Milosevic M, et al. Prognostic Value of Pretreatment Circulating Neutrophils, Monocytes, and Lymphocytes in Oropharyngeal Cancer Stratified by Human Papillomavirus Status. Cancer February 2015;15:545-555

6. Chun S, Shin K, Kim KH, et al. The Neutrophil-Lymphocyte Ratio Predicts Recurrence of Cervical Intraepithelial Neoplasia. Journal of Cancer 2017;8:2205-2211

7. Lopes RVC, Teixeira JA, Marchioni D, et al. Dietary intake of seleceted nutrients and persistence of HPV infection in men. Int J Cancer 2017;15;141(4):757-765

8. Milstone LM, Hu RH, Dziura JD, et al. Impact of epidermal desquamation on tissue stores of iron. J Dermatol 2012;67(1):9-14

9. Sedjo RL, Fowler BM, Schneider A, et al. Folate, Vitamin B12, and Homocysteine Status: Findings of No Relation Between Human papillomavirus Persistence and Cervical dysplasia. Nutrition 2003;19(6):497-502

10. De Felice F, Tombolini M, Abate G, et al. Prognostic Significance of the Neutrophil/Lymphocyte Ratio in patients with Non-Human Papilloma Virus-Related Oropharyngeal Cancer: A Retrospective Cohort Study. Oncology 2019;96:8-13

11. Ilktac A, Dogan B, Ersoz C, et al. The relationship of neutrophil to lymphocyte ratio with testicular cancer. Int Braz J Urol 2020;46;101-7

12. Dupin N. Genital Warts. Clinic in Dermatalogy 2004;22:481-486

13. Brentjens MH, Yeung-Yue KA, Lee PC, et al. Human papillomavirus: a review. Dermatol Clin 20(2) $2002 ;: 315-331$

14. Schiffman M, Kjaer SK. Natural history of anogenital human papillomavirus infection and neoplasia. J Natl Cancer Inst Monograph 2003;31:14-9

15. Choudhury SA, Choudhury NA, Humphrey AD, et al. Higher prevalence of human papillomavirusrelated cervical precancerous abnormalities in HIV-infected compared to HIV-Uninfected Women. Med. Assoc. 2016;108:19-23

16. Martinez-Zapien D, Ruiz FX, Poirson J, Mitschler A, et al. Structure of the E6/E6AP/p53 complex required for HPV-mediated degradation of p53. Nature 2016;529:541-545 
17. Trellakis S, Farjah H, Bruderek K, et al. Peripheral blood neutrophil granulocytes from patients with head and neck squamous cell carcinoma functionally differ from their counterparts in healthy donors. Int J Immunopathol Pharmacol. 2011;24:683-693

18. Fernandes PC Jr, Garcia CB, Micheli DC, et al. Circulating neutrophils may play a role in the host response in cervical cancer. Int J Gynecol Cancer. 2007;17:1068-1074

19. Gregory AD, Houghton AM. Tumor-associated neutrophils: new targets for cancer therapy. Cancer Res.2011;71:2411-2416

20. Siegel EM, Patel N, Lu B, et al. Circulating Biomarkers of Iron Storage and Clearance of incident Human Papillomavirus Infection. 2012;21(5):859-865

21. Li W, Tao L, Zhang L, et al. Prognostic role of lymphocyte to monocyte ratio for patients with pancreatic cancer: a systematic review and meta-analysis. Onco Targets and Therapy 2017;10:33913397

22. Wu J, Chen M, Liang C, et al. Prognostic value of the pretreatment neutrophyl-to-lymphocyte ratio in cervical cancer: a meta-analysis and systematic review. Oncotarget 2017;8(8):13400-13412

23. Li SW, Yuan W, Zhao B, et al. Positive effect of HPV status on prognostic value of blood lymphocyteto-monocyte ratio in advanced cervical carcinoma. Cancer cell Int 2016;16:54

24. Farzaneh F, Faghih N, Hosseini MS, et al. Evaluation of Neutrophil-Lymphocyte Ratio as a Prognostic Factor in Cervical Intraepithelial Neoplasia Recurrence. APJCP 2019;20(8):2365

\begin{tabular}{lllll}
\hline Parameters & Pearson's Coefficient & $\mathrm{p}$ & $\mathrm{R}$ square & Coefficient \\
\hline Age & 0,25 & 0.01 & 0.06 & 0.25 \\
Nux & & 0.93 & & \\
Vit B12 $(\mathrm{pg} / \mathrm{ml})$ & & 0.37 & & \\
Vit D $(\mathrm{ng} / \mathrm{ml})$ & & 0.95 & & \\
Ferritin(ng/ml) & & 0.47 & \\
Leucocyt $\left(10^{*} 3 / \mathrm{uL}\right)$ & & 0.42 & \\
Neutrophil (N) (\%) & & 0.49 & \\
Lymphocyte(L) (\%) & & 0.30 & \\
Monocyte (M) (\%) & & 0.88 & \\
Hb (g/dL) & & 0.43 & \\
MCV (fL) & 0.20 & 0.04 & 0.04 & \\
Platelet $\left(10^{*} 3 / \mathrm{uL}\right)$ & & 0.5 & \\
MPV (fL) & & 0.7 & \\
N/M & & 0.93 & \\
N/L & & 0.48 & \\
L/M & 0.58 & \\
\hline
\end{tabular}

Table 1: The results of the Pearson Correlation analysis and lineer regression between lesion numbers and blood parameters, $\mathrm{p}<0.05$ is accepted significant.

\begin{tabular}{llll}
\hline $\begin{array}{l}\text { Groups for the lesion } \\
\text { number }\end{array}$ & Recurrent Status n=29 & Recurrent Status n=29 & Total \\
\hline & $(-)$ & $(+)$ & \\
{$[?] 5$} & $25(71.4 \%)$ & $10(28.6 \%)$ & 35 \\
$5-10$ & $20(71.4 \%)$ & $8(28.6 \%)$ & 28 \\
$>10$ & $23(67.6 \%)$ & $11(32.4 \%)$ & 34 \\
Total & $68(70.1 \%)$ & $29(29.9 \%)$ & \\
\hline
\end{tabular}


Table 2: The results of analysis between lesion numbers and recurrent status, $\mathrm{p}>0.05$

\begin{tabular}{|c|c|c|c|c|c|c|}
\hline Parameters & Group $1 \mathrm{n}=99$ & Group $2 \mathrm{n}=94$ & $\mathbf{p}$ & $\begin{array}{l}\text { Recurrent } \\
\text { status }\end{array}$ & $\begin{array}{l}\text { Recurrent } \\
\text { status }\end{array}$ & $\mathrm{p}$ \\
\hline & & & & $(+) \mathrm{n}=29$ & $(-) \mathrm{n}=70$ & \\
\hline Age & $39.59 \pm 10.94$ & $40.04 \pm 10.3$ & 0.051 & $37.27 \pm 10.61$ & $36.63 \pm 11.5$ & 0.79 \\
\hline $\begin{array}{l}\text { Lesion } \\
\text { number }\end{array}$ & & & & $10.5 \pm 8.23$ & $10.66 \pm 8.89$ & 0.93 \\
\hline $\begin{array}{l}\text { Vit B12 } \\
(\mathrm{pg} / \mathrm{mL})\end{array}$ & $341.09 \pm 155.99$ & $342.54 \pm 143.84$ & 0.95 & $318.9 \pm 132.5$ & $355.36 \pm 164.1$ & 0.28 \\
\hline $\begin{array}{l}\text { Vit D } \\
(\mathrm{ng} / \mathrm{mL})\end{array}$ & $58.81 \pm 52.93$ & $43.95 \pm 92.3$ & 0.057 & $22.45 \pm 9.79$ & $22.81 \pm 8.16$ & 0.85 \\
\hline $\begin{array}{l}\text { Ferritin } \\
(\mathrm{ng} / \mathrm{mL})\end{array}$ & $132.59 \pm 86.49$ & $106.81 \pm 64.5$ & 0.02 & $122.47 \pm 63.5$ & $136.29 \pm 95.84$ & 0.47 \\
\hline $\begin{array}{l}\text { Leucocyte } \\
\left(10^{*} 3 / \mathrm{uL}\right)\end{array}$ & $7.67 \pm 1.72$ & $7.65 \pm 1.94$ & 0.91 & $7.70 \pm 2.24$ & $7.68 \pm 1.43$ & 0.96 \\
\hline $\begin{array}{l}\text { Neutrophil } \\
(\mathrm{N})(\%)\end{array}$ & $56.09 \pm 7.93$ & $53.33 \pm 8.00$ & 0.01 & $57.86 \pm 7.83$ & $55.17 \pm 7.98$ & 0.12 \\
\hline $\begin{array}{l}\text { Lymphocyte } \\
\text { (L) }\end{array}$ & $32.91 \pm 7.54$ & $34.63 \pm 7.26$ & 0.1 & $30.98 \pm 7.63$ & $33.86 \pm 7.43$ & 0.08 \\
\hline $\begin{array}{l}\text { Monocyte } \\
\text { (M) }\end{array}$ & $7.51 \pm 1.66$ & $8.16 \pm 1.84$ & 0.01 & $7.42 \pm 1.97$ & $7.54 \pm 1.53$ & 0.74 \\
\hline $\mathrm{Hb}(\mathrm{g} / \mathrm{dL})$ & $15.1 \pm 1.22$ & $15.13 \pm 1.11$ & 0.9 & $15.53 \pm 1.13$ & $14.93 \pm 1.23$ & 0.02 \\
\hline $\begin{array}{l}\mathrm{RBC} \\
\left(10^{*} 3 / \mathrm{uL}\right)\end{array}$ & $5.34 \pm 0.48$ & $5.41 \pm 0.41$ & 0.28 & $5.46 \pm 0.42$ & $5.28 \pm 0.5$ & 0.09 \\
\hline MCV (fL) & $87.5 \pm 4.16$ & $86.75 \pm 4.18$ & 0.049 & $87.85 \pm 3.8$ & $87.5 \pm 4.3$ & 0.77 \\
\hline $\begin{array}{l}\text { Platelet } \\
\left(10^{*} 3 / \mathrm{uL}\right)\end{array}$ & $258.46 \pm 51.22$ & $251.38 \pm 57.94$ & 0.38 & $257.92 \pm 34.5$ & $260.12 \pm 56.82$ & 0.16 \\
\hline $\begin{array}{l}\text { Platelet } \\
\text { volume (fL) }\end{array}$ & $7.44 \pm 1.34$ & $7.59 \pm 1.62$ & 0.48 & $7.74 \pm 1.71$ & $7.32 \pm 1.13$ & 0.84 \\
\hline $\mathrm{N} / \mathrm{M}$ & $7.73 \pm 2.14$ & $6.96 \pm 2.12$ & 0.01 & $8.2 \pm 2.15$ & $7.52 \pm 2.14$ & 0.14 \\
\hline $\mathrm{N} / \mathrm{L}$ & $1.89 \pm 0.91$ & $1.72 \pm 0.86$ & 0.17 & $2.16 \pm 1.22$ & $1.77 \pm 0.72$ & 0.05 \\
\hline
\end{tabular}

Table 3: The comparative results with mean \pm standard deviations of the groups and subgroups in terms of recurrent status between parameters, $\mathrm{p}<0.05$ is accepted significant

\begin{tabular}{llllll}
\hline Parameters & AUC \pm Std Error & $\mathrm{p}$ & Sensititivity & Spesificity & Cutoff value \\
\hline Ferritin (ng/ml) & $0.57 \pm 0.04$ & 0.08 & 0.49 & 0.66 & 139.74 \\
MCV (fl) & $0.55 \pm 0.04$ & 0.16 & 0.19 & 0.06 & 91.15 \\
Neutrophyl (N) (\%) & $\mathbf{0 . 5 9} \pm \mathbf{0 . 0 4}$ & $\mathbf{0 . 0 1}$ & $\mathbf{0 . 4 9}$ & $\mathbf{0 . 2 9}$ & $\mathbf{5 6 . 4 5}$ \\
Monocyte (M) (\%) & $\mathbf{0 . 3 9} \pm \mathbf{0 . 0 4}$ & $\mathbf{0 . 0 1}$ & $\mathbf{0 . 9 8}$ & $\mathbf{0 . 9 7}$ & $\mathbf{4 . 9 1}$ \\
N/M & $\mathbf{0 . 6 1} \pm \mathbf{0 . 0 4}$ & $\mathbf{0 . 0 0 5}$ & $\mathbf{0 . 4 8}$ & $\mathbf{0 . 2 8 7}$ & $\mathbf{7 . 8 2 5}$ \\
\hline
\end{tabular}

Table 4: The results for the AUC of ROC with the best cutoff value and sensitivity and spesificity rates (95\% Confidence Interval)

Figure 1: Receiver Operating Curves for the ferritin level (A) and MCV (Midcorpuscular volume) (B), respectively. 
Figure 2: Receiver Operating Curves for the Neutrophyl (N) percentage (A), Monocyte (M) Percentage (B), and N/M (C), respectively.
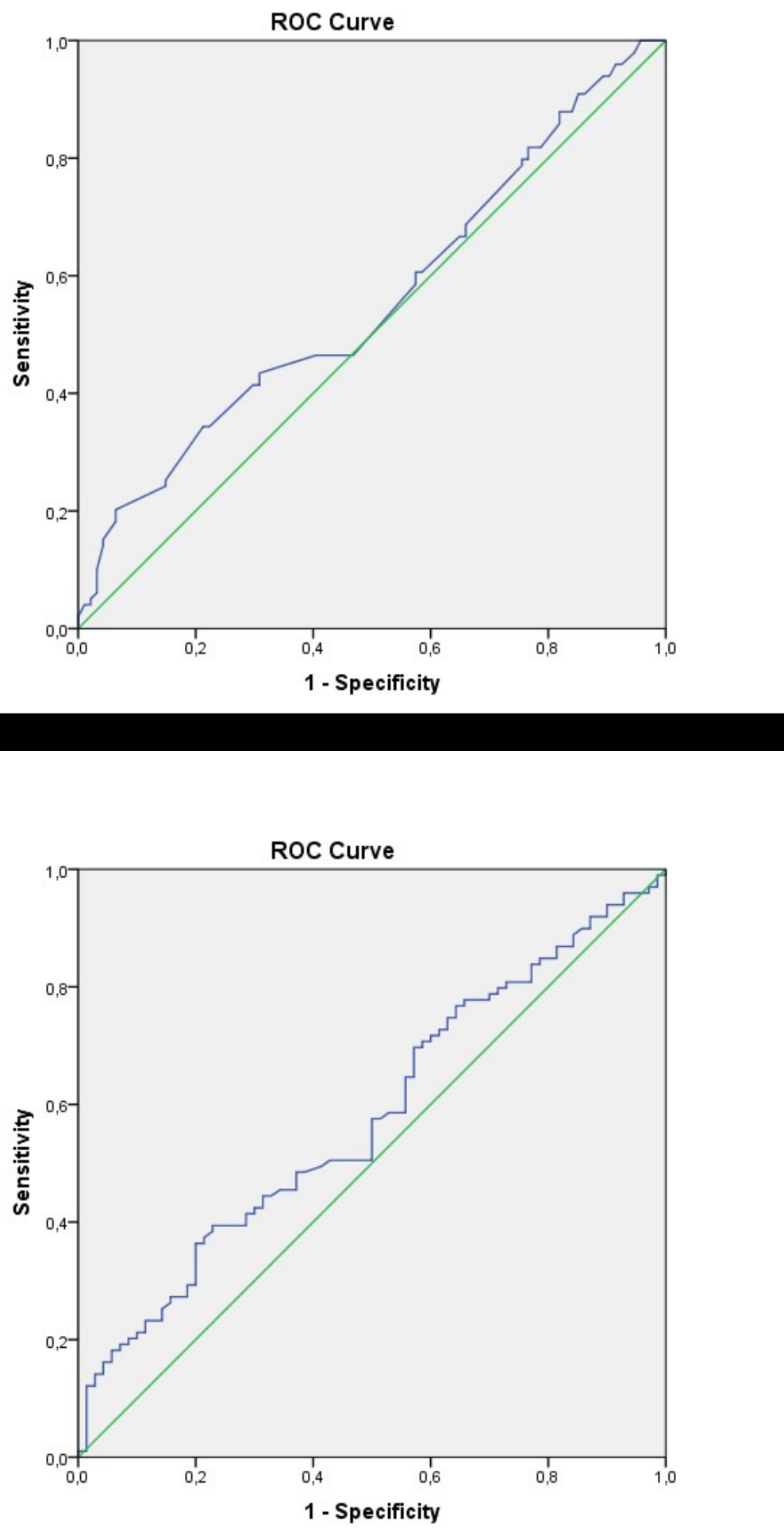

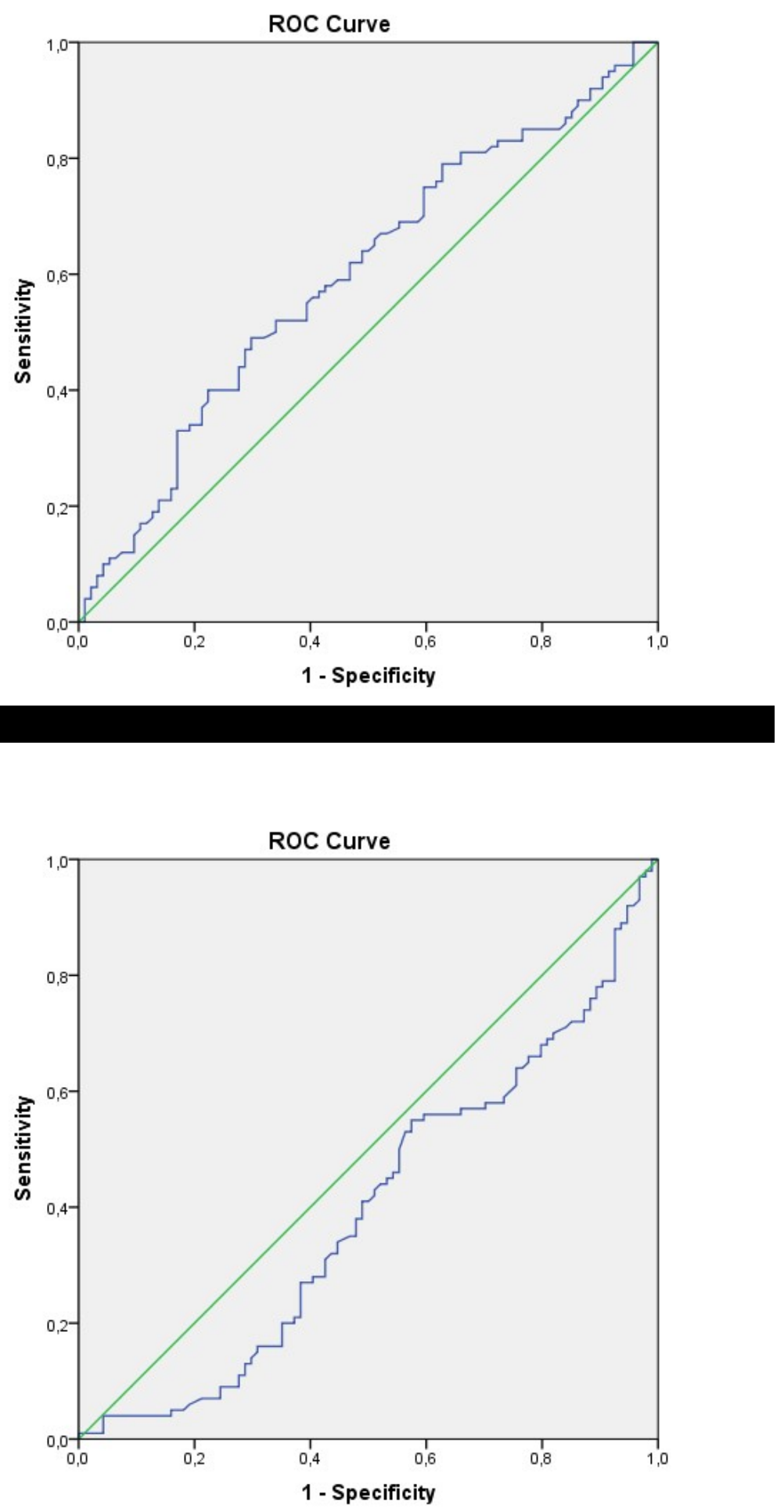


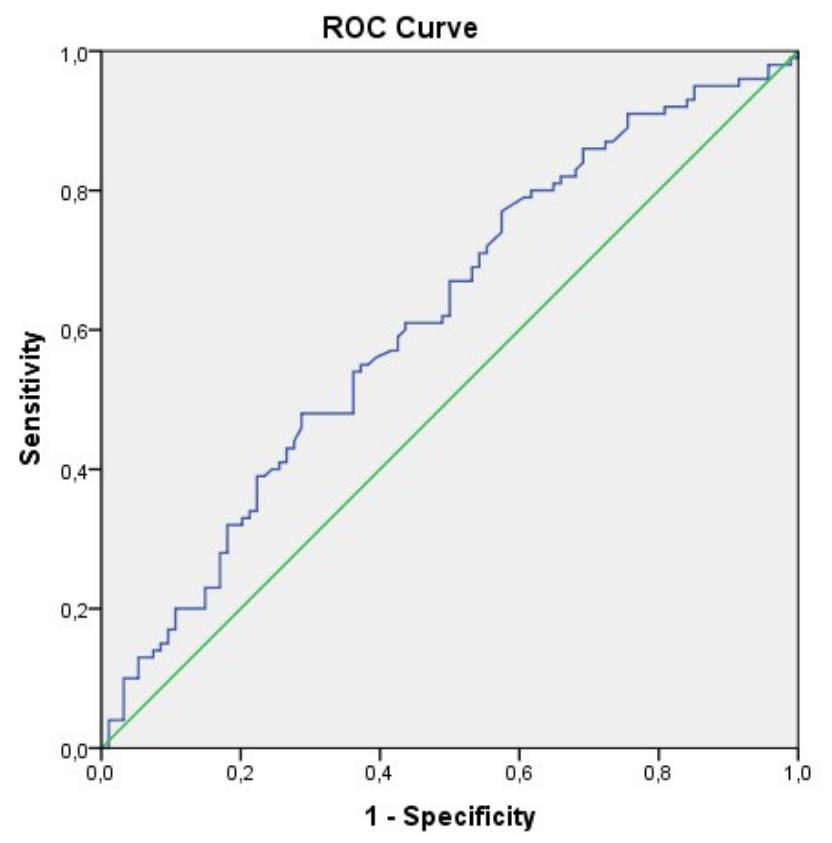

